\title{
O "estatativismo" como uso militante da quantificação
}

\section{Emmanuel Didier ${ }^{*}$ (1) Isabelle Bruno** (1)}

\section{Resumo}

Este artigo apresenta o estatativismo. Trata-se tanto de um conceito que descreve um conjunto de práticas estatísticas voltadas para a emancipação, como de uma palavra de ordem que convoca atores sociais a utilizarem-se do poder da quantificação em suas lutas, ao invés de rejeitá-lo e entregá-lo às instituições poderosas. Quatro formas de estatativismo são apresentadas: mostrar as contradições internas das instituições, flexibilizar as regras, identificar grupos sociais em luta e propor indicadores alternativos. $\diamond$

Palavras-chave: estatativismo, sociologia da quantificação, emancipação, instituições, realidade.

\section{Le « statactivisme » comme usage militant de la quantification}

Résumé

Cet article présente le statactivisme. II s'agit à la fois d'un concept décrivant un ensemble de pratiques statistiques qui visent à l'émancipation et d'un mot d'ordre enjoignant les acteurs sociaux à s'emparer de la force de la quantification dans leurs luttes sociales plutôt que de la refuser en la laissant aux institutions puissantes. Quatre types de statactivisme sont présentés : montrer les contradiction internes des institutions, prendre des libertés avec les règles, identifier des groupes sociaux en lutte, et proposer des indicateurs alternatifs.

Mots clefs : statactivisme, sociologie de la quantification, émancipation, institutions, réalité.

* Ecole Normale Supérieure-E.H.E.S.S., Paris, France.

** Université de Lille, Lille, France.

$\checkmark$ Uma versão preliminar deste texto foi publicada como introdução ao livro Statactivisme (Bruno; Didier; Prévieux, 2014).

- Tradução para o português de Liana Fernandes. 
P arece não haver melhor exemplo, hoje, de uma autoridade capaz de desarmar qualquer crítica do que um número ou uma rede de números. A quantificação frequentemente tem um papel de destaque na produção da "autoridade dos fatos", que tem estado no centro das dificuldades encontradas pela Escola de Frankfurt em seu esforço para construir uma teoria da emancipação (Genel, 2013; Bruno, 2015).

Acreditamos que, para um pensamento crítico, uma das formas de enfrentar a autoridade dos fatos encontra-se, então, na distinção, proposta por Luc Boltanski em De la Critique, entre, por um lado, "a realidade" que "tende a confundir-se com o que parece ser sustentado de alguma forma somente por sua força, isto é, pela ordem", e por outro, "o mundo" como "tudo o que acontece", o conjunto dos "acontecimentos ou experiências cuja possibilidade não se inseriu no desenho da realidade" (Boltanski, 2009, p. 93-94). A primeira se organiza a partir de "formatos, determinados sob a coação de um poder institucional", que tendem a "abordar o mundo em sua totalidade" (Boltanski, 2009, p. 140). O segundo, "imerso no fluxo da vida", consiste em experiências difíceis de "expressar em palavras" (Boltanski, 2009, p. 94). Essa oposição nos parece muito útil para compreender os efeitos de dominação e, também, a força crítica atribuídos às estatísticas.

Apesar das imprecisões que o termo suscita, pode-se concordar em chamar de neoliberal o estado atual da realidade. Esta, em grande medida, é moldada e consolidada pelas estatísticas, o que, em si, não deveria surpreender. Como se pode ver pela etimologia da palavra, a estatística esteve ligada, desde sua origem, ao poder, em particular ao poder do Estado (Bourdieu, 2012), contudo, nenhum dos dois permaneceu imutável. A instrumentalização efetiva do estado neoliberal é única (Desrosières, 2008). Seu núcleo duro consiste numa avaliação quantitativa e comparativa permanente da atividade dos agentes, colocados assim em concorrência por meio de uma tecnologia que se pode chamar de benchmarking (Bruno; Didier, 2013). A avaliação, hoje, é tão sistemática que tende a se confundir com a própria ação. Ora, "uma vez que os procedimentos de quantificação 
são codificados e rotinizados, seus produtos são reificados. Eles tendem a tornar-se 'a realidade', através de um efeito catraca irreversível" (Desrosières, 2008 , p. 12). Somos então obrigados a atingir metas quantificadas e a intensificar indefinidamente nosso desempenho conforme os valores definidos pelo indicador. A prática remete a uma linha base de reprodução ótima do mesmo, a despeito de variações, experimentos, acidentes e imprevistos. A inserção de atores em redes de quantificação cada vez mais fechadas parece, portanto, ser um dos principais instrumentos de estreitamento das possibilidades práticas que lhes são oferecidas.

Com o desenvolvimento do benchmarking, a estatística tornou-se alvo de muitas críticas e, por fim, de rejeição por princípio. Os primeiros a perder com esses novos métodos de avaliação neoliberais, entre os quais podemos citar os profissionais da saúde, serviço social, educação, justiça, informação e cultura, que se reuniram no movimento Appel des appels ${ }^{1}$ (Gori et al., 2009), sentiram imediatamente os efeitos nocivos das técnicas de gerência pela performance, que consistem em quantificar e comparar os resultados obtidos no exercício de suas profissões. Esses profissionais denunciaram tais técnicas em virtude da impenetrabilidade pela quantificação daquilo que o sociólogo Florent Champy chama de "práticas prudenciais", ou seja, a atenção a casos particulares, a situações complexas e específicas (Champy, 2009). Contudo, outros autores generalizaram essa denúncia para qualquer quantificação, seja ela qual for, valendo-se especialmente de argumentos provenientes de diferentes correntes da psicanálise lacaniana (ECF, 2008; Milner, 2011) ou do paradigma da dádiva (Caillé, 2012). Isso se deu de tal forma que estatísticas que têm uma relação muito distante com o benchmarking e que, até então, gozavam de uma imagem bastante progressista, viram-se alvos da crítica.

${ }^{1}$ N. T.: O Appel des appels é um movimento criado em 2008 pelo psicanalista Roland Gori e apoiado pela sociedade civil que visa a união de profissionais de diferentes setores do serviço público em oposição à realização de reformas e à avaliação da ação pública a partir principalmente de critérios econômicos. Mais informações em http://www.appeldesappels.org/. 
No entanto, se hoje as estatísticas são prontamente criticadas por sua conivência com o poder e a sanção, a história de seus vínculos com a reforma social e a emancipação é igualmente longa e rica. As estatísticas também mostraram, no passado, que outra realidade era possível ou tornaram reais outras possibilidades. É por isso que não reagimos como aqueles que as rejeitam totalmente e gritam "Não à quantofrenia! Não aos números! Sim às qualidades!", porque, ao fazê-lo, deixam o monopólio desses instrumentos para os poderosos. Ora, não há razão para que a quantificação esteja sempre do lado do Estado e do capital. É importante sair dessa visão centrada no Estado, que é particularmente dominante na França (Didier, 2021), e destacar outros modos de produção e outros usos dos números. Para explorar o campo dessas práticas militantes, usando a estatística como recurso de resistência, cunhamos um termo para dar nome à coisa: "estatativismo".

Este neologismo deve, assim, ser entendido tanto como um slogan a ser brandido nas lutas quanto como um conceito descritivo, utilizado para qualificar experimentos voltados à reapropriação do poder emancipatório da estatística. Desde $2012{ }^{2}{ }^{2}$ sucessivos trabalhos realizados por grupos de pesquisadores, assim como por ativistas, e artistas, possibilitaram, por um lado, mapear um conjunto de práticas relacionadas a essa aspiração e, por outro, explicitar as tensões e questões em que esse uso da quantificação nos mergulhou. Esses esforços resultaram em muitas publicações que alimentaram e exemplificaram o conceito de estatativismo. Primeiramente, um livro possibilitou sua ampla difusão na França (Bruno; Didier; Prévieux, 2014). Depois, uma edição especial em inglês da revista italiana Partecipazione e conflito tornou-o mais amplamente acessível (Bruno; Didier; Vitale, 2014). Pôde-se, então, mostrar a importância do estatativismo na luta contra o abuso de poder por parte da polícia na França (Didier, 2018) ou, ainda,

${ }^{2}$ No dia 15 de maio de 2012, foi organizada em Paris uma conferência sobre o "estatativismo" que deu origem à obra Statactivisme : comment lutter avec des nombres (Bruno; Didier; Prévieux, 2014). 
no Brasil, como mostra o número especial da revista Statistique et société (v. 7, n. 1, 2019), que teve como foco a quantificação ativista no país.

Por fim, o conceito foi utilizado em inúmeras ocasiões para analisar a pandemia da COVID-19, que também é, sem dúvida, uma pandemia de números. Por exemplo, os indicadores utilizados pelos poderes públicos, como o número de infecções ou de óbitos, puderam ser questionados, pois focariam a atenção nos problemas médicos, desviando-a das consequências socioeconômicas das políticas implementadas, as quais, por sua vez, seriam pouco representadas estatisticamente (Didier, 2020). Por outro lado, as tensões éticas associadas aos modelos epidemiológicos quantitativos foram apontadas num artigo publicado na Nature que convida, sob a bandeira do estatativismo, estatísticos e modeladores a atuar de forma mais "transparente e despretensiosa", a divulgar informações como as limitações de seus dados, e também a admitir que o trabalho científico não está à parte do mundo social, de suas contingências e incertezas, de seus conflitos e relações de poder (Saltelli et al. 2020).

O estatativismo tem um significado mais amplo e outro restrito. Em primeiro lugar, designa todas as práticas estatísticas que servem para criticar e se emancipar de uma autoridade, seja ela qual for. Essas práticas estatísticas já existem há muito tempo - voltaremos a elas. Já num segundo sentido, mais restrito, algumas dessas práticas são mais especificamente adaptadas ao tipo de poder exercido no âmbito da governamentalidade neoliberal; elas visam emancipar-se dos métodos de governo próprios desse modelo. Dito de outra maneira, lembremo-nos do argumento de Desrosières (2003), segundo o qual podemos listar cinco formas diferentes de Estado, todas as quais se utilizam da ferramenta estatística para agir, mas cada uma de acordo com uma modalidade específica. Por exemplo, o Estado keynesiano recorre à contabilidade nacional, pois ela Ihe permite controlar os fluxos úteis para a política de estímulo ao consumo, enquanto o Estado neoliberal prefere mobilizar indicadores de desempenho e metas quantificadas para avaliar a eficiência de seus serviços. Há uma correspondência entre a forma de ação 
pública e a ferramenta estatística (Desrosières, 2003). Mas essa adequação também se aplica às ferramentas de crítica, inclusive quando estas são quantitativas. Cada forma de autoridade tem sua própria forma de oposição. Nesse contexto, o estatativismo assume um significado particular quando designa os métodos especificamente vinculados ao governo neoliberal.

Para fazer frente a essa governamentalidade que se infiltra num grande número de mundos normalmente compartimentados, o estatativismo permite ir além das fronteiras estabelecidas. O colóquio de maio de 2012 reuniu pesquisadores especializados no estudo da estatística, ativistas acostumados a utilizar números para avançar suas causas e, por fim, artistas plásticos cuja inspiração está na quantificação e nas técnicas contemporâneas de gestão por números. Mostramos, assim, que a crítica acadêmica, a crítica social e a crítica artística convergem.

Se o estatativismo consiste em colocar a estatística a serviço da emancipação, podemos distinguir quatro maneiras diferentes de proceder. A primeira indica caminhos para o estudo do estatativismo em sentido amplo; ela permite, por meio de uma revisão histórica, questionar o grau de radicalidade da crítica estatística. Em seguida, analisaremos práticas mais contemporâneas do estatativismo; elas podem ser mais ou menos específicas ao governo neoliberal, pois as formas de autoridade do passado sobrevivem ao surgimento de novas, e o mesmo acontece com as formas críticas. A segunda parte mostra como se dribla - individual e, muitas vezes, secretamente - as regras de prestação de contas de forma a se apropriar dos resultados do exercício. A terceira mobiliza as estatísticas para consolidar categorias coletivas que forneçam bases para reivindicar direitos e defender interesses. Por fim, a quarta produz indicadores alternativos para redefinir o sentido de nossas ações. 


\section{Crítica radical ou reformista, exemplos retirados do passado}

A história da ligação entre estatística e emancipação social é antiga. Voltemos ao passado para melhor acompanhar a trajetória das inovações estatísticas nesse sentido e, assim, melhor compreender como, ao longo do tempo, elas foram aceitas pelo público.

Um exemplo interessante é oferecido pelo livro Les Héritiers (1964), ${ }^{3}$ de Pierre Bourdieu e Jean-Claude Passeron, no qual os autores mostraram que, na França, a escola não atenuava as desigualdades culturais entre as crianças; pelo contrário, as agravava ao reconhecer e validar o capital cultural daquelas que o recebiam de suas famílias. Isso se demonstrou por meio do cruzamento de variáveis, em particular a Classificação de Ocupação ${ }^{4}$ do pai com diferentes medidas de vida estudantil e sucesso escolar, a fim de mostrar que são os filhos de pais pertencentes a categorias sociais que já têm um capital cultural significativo que conseguem ingressar nas carreiras acadêmicas mais prestigiosas. Dessa forma, essa obra demonstrou o que todos, em certa medida, já sabiam por experiência própria. Mas ela totalizou uma série de experiências individuais as quais objetivou estatisticamente, dando assim, a cada um, uma base para entender como essa experiência era fruto, menos de sua virtude acadêmica pessoal, e mais de um sistema de dominação imposto a todos. Daí um efeito de remoção da culpa.

É interessante destacar aqui que as classificações utilizadas e cruzadas eram oficiais, quer dizer, baseavam-se numa realidade consolidada por instituições estatais. Vindo do próprio "sistema", elas mostram suas contradições internas. O serviço público de educação nacional pretende remediar as injustiças, apelando à ética do dom dos professores, que supostamente oferecem seu conhecimento pelo interesse geral, mas, de fato, apenas restitui e perpetua a injustiça.

${ }^{3}$ N.T.: Publicado em português como Os herdeiros: os estudantes e a cultura. Florianópolis: Editora da UFSC, 2013.

${ }^{4}$ N.T.: No francês, "Professions et catégories socioprofessionnelles". 
Pode-se, assim, concluir, conforme Luc Boltanski, que a crítica estatística não nos permite captar o que este autor chama de críticas existenciais. Essas críticas radicais, que geralmente são provenientes de artistas, consistem em extrair do mundo elementos importantes, ainda que estes não tenham sido institucionalizados de uma forma ou de outra (Boltanski, 2014). Les Héritiers não tinha a intenção de incitar questionamentos sobre a própria existência da escola. Em consonância com a dicotomia de inspiração marxista entre reformismo e radicalismo revolucionário que ocorria na época, o livro propunha, sobretudo, uma crítica reformista construída a partir de categorias da realidade institucional. A obra criticava a instituição a partir disso. De toda forma, a publicação desse livro foi um grande sucesso. Segundo Boltanski, a obra teria até mesmo "desempenhado um papel significativo na mudança de espírito coletivo que precedeu maio de 1968".

A longa polêmica sobre o índice de preços na França é outro exemplo histórico do alcance crítico das estatísticas (Desrosières, 2014; Touchelay, 2014). Historiadores mostram a trajetória dos índices alternativos de preços do início da década de 1970 até os anos 1990. Nesse período, a Confederação Geral do Trabalho (CGT) divulgou os resultados de um índice de elaboração própria, diferente do apresentado pelo Instituto Nacional de Estatística e Estudos Econômicos (INSEE). O argumento da CGT era de que o índice do INSEE se baseava em premissas muito alinhadas ao modo de consumo das classes médias, muito diferente daquele das classes trabalhadoras.

Inicialmente, o índice da CGT teve grande sucesso e foi utilizado juntamente com o do INSEE - em negociações salariais. Mesmo a mídia, por vezes, levava em consideração suas variações (Piriou, 1992). No entanto, a partir do final da década de 1980, ele começou a cair em desuso, até que a CGT decidiu interromper completamente sua elaboração durante os anos 1990. Como esse índice pôde ser aceito num primeiro momento, até perder gradualmente o apelo e, finalmente, desaparecer por completo? Desrosières (2014) oferece uma explicação sociológica: ele considera que 
os argumentos estatísticos atendem a condições de recepção que lhes são mais ou menos favoráveis e que podem mudar com o tempo.

De qualquer forma, o fato é que os desenvolvedores desses índices concordavam quanto ao aparato metodológico que permitia calculá-los e aos seus usos institucionais. Ainda que tenha modificado os produtos considerados na "cesta" do consumidor, a CGT apropriou-se da arquitetura dos conceitos econômicos que tornam tal índice relevante. Nesse sentido, a crítica foi novamente reformista, não radical.

No ano em que a CGT lançou seu índice, o artista alemão Hans Haacke montou uma exposição na galeria nova-iorquina John Weber com objetivos semelhantes, pode-se dizer, aos do já citado livro Os herdeiros. ${ }^{5}$ No dia da inauguração, o público encontrou apenas uma mesa, sobre a qual havia questionários com cerca de vinte questões sobre características sociodemográficas e opiniões sobre eventos correntes. Poucos dias depois, Haacke acrescentou à instalação os resultados de sua pesquisa na forma de quadros representando gráficos e histogramas. Esses mostraram que a grande maioria dos visitantes tinha ligações profissionais com o mundo da arte, pertencia a uma classe média educada, com recursos financeiros limitados e que, predominantemente, se declarava "liberal", no sentido americano do termo. Haacke gerou assim um contraste com outra exposição que estava fazendo em Nova York na mesma época, onde exibiu, sem comentários, as muitas e opulentas afiliações dos curadores do Museu Guggenheim aos conselhos administrativos de grandes corporações capitalistas. Assim, dentro dos marcos institucionais do mundo da arte - prestigiosas galerias de Nova York e um museu - e por meio de categorias muito consolidadas, Haacke expôs a divisão político-social que separava radicalmente o público da arte contemporânea e a elite que a patrocina. A crítica estatística foi mais uma vez bastante reformista, na medida em que se apoiou nas instituições que pretendia abalar.

5 Haacke também publicou posteriormente um livro de diálogos com Pierre Bourdieu (Bourdieu; Haacke, 1994). 
Essas três experiências, muito em consonância com o espírito dos anos 1970, têm autores que, mesmo não sendo todos especialistas em estatística, nem de longe estavam em desvantagem em relação a esses. Bourdieu fazia parte da longa tradição sociológica de utilizar a estatística, que se pode remontar ao Suicídio de Durkheim. Além disso, tinha vínculos pessoais com estatísticos do Instituto Nacional de Estatística e Estudos Econômicos (INSEE) desde a década de 1950 e chegou a lecionar na Escola Nacional de Estatística e Administração Econômica (ENSAE) - que forma os administradores do Instituto - no mesmo ano do lançamento de Les héritiers. Da mesma forma, a CGT deu continuidade a uma longa tradição de produção de estatísticas sociais que remonta, através dos sindicatos, ao final do século XIX (Topalov, 1994). Quanto a Hans Haacke, se ele aparentemente produziu seus questionários sozinho, também foi, de alguma forma, auxiliado sociologicamente por Howard Becker. Os representantes dessa geração de estatativistas, portanto, usaram os ricos recursos intelectuais e institucionais aos quais tinham acesso para produzir estatísticas.

Com base em elementos da realidade estabelecidos e institucionalizadosclassificações, séries de produtos, rede de distribuição e de divulgação de um meio etc. -, essas estatísticas não questionam radicalmente essa realidade que, ao mesmo tempo, denunciam; em vez disso, tornam possível influenciá-la, reformá-la. Bourdieu e Passeron não questionaram a existência da escola, mas tornaram possível uma reforma; a CGT construiu uma ferramenta que lhe permitiu exercer mais influência, mas dentro do quadro estabelecido de negociações salariais; por fim, Haacke ajudou a fundar um novo movimento chamado "Crítica institucional", que ganhou espaço no meio artístico existente. $\mathrm{O}$ acesso a recursos estatísticos institucionais teve, portanto, o efeito conjunto de possibilitar a reforma e estabilizar o quadro em que essas reformas encontraram seu lugar. Estatativismo era, para usar o título do catálogo de Haacke, Framing and being framed (1975), quer dizer, aceitar colocar-se em um arcabouço pré-estabelecido, o que em si 
não é radical, mas, ao mesmo tempo, encontrar nele margens de liberdade suficientes para modificá-lo, sendo, portanto, reformador.

Vamos agora pular os quarenta anos que nos separam desses tempos heroicos e explorar a atual descendência desse uso da estatística.

\section{Operações: burlar a regra}

A escala de aplicação das estatísticas institucionais mudou muito desde os anos 1970. Antes, elas se aplicavam a grandes instituições, grandes agregados - por exemplo, o sistema escolar, negociações salariais por ramo, o mundo da arte -, e o estatativismo desenvolvia-se nessa escala. Hoje, nas instituições, elas também são usadas para avaliar agentes individuais. Em muitos setores, e cada vez com mais frequência, cada pessoa deve manter um relatório quantificado de suas próprias atividades, o qual é usado regularmente para sua autoavaliação em comparação com outras pessoas ou equipes em relação a objetivos quantificados pré-estabelecidos.

Desse modo, uma prática estatativista, hoje muito difundida, ainda que bastante discretamente, para atores situados na base da hierarquia, consiste em deixar espaço de manobra no âmbito dos relatórios estatísticos que lhes são impostos. Essa forma de resistir à avaliação consiste em comportar-se exatamente como os dirigentes, quer dizer, a não confiar realmente na letra da regra, a fim de adaptá-la num sentido que convenha mais ao que ela se aplica. Mas a principal diferença entre o topo e a base da hierarquia é que, na base, esses reajustes são mantidos em segredo, ou, mais precisamente, são realizados discretamente, porque são considerados ilegítimos, enquanto no topo podem ser proclamados como sendo nada mais do que adaptações salutares da regra, demonstrações de complacência e de flexibilidade (Boltanski, 2009). A emancipação estatativista, neste caso, consiste, para os dominados, por um lado, em uma interpretação livre da regra e, por outro, em tornar pública e legítima uma prática corrente, mas mantida encoberta. 
Para ilustrar esse ponto, escolhemos o caso da polícia, que é interessante porque sua função é justamente fazer cumprir as regras da vida social. A polícia foi, durante os anos 2000, submetida ao que seus detratores chamam pejorativamente de "política dos números" e seus bajuladores de "cultura do resultado". Costuma-se situar o nascimento desse sistema na cidade de Nova York, durante o primeiro mandato do prefeito republicano Rudy Giuliani, entre 1994 e 2001. Seu chefe de polícia, William Bratton, instalou, na época, um sistema de gestão policial denominado Compstat (que, para uns, significa "computer statistics" [estatística computacional] e, para outros, "comparative statistics" [estatística comparada]), que se baseia fundamentalmente na quantificação da atividade dos agentes. Os delegados de cada distrito eram responsáveis por quantificar as suas atividades, de forma a apresentarem relatórios muito regulares à mais alta hierarquia policial, o que lhes permitiria provar que tomaram iniciativas e foram particularmente "proativos". Assim que esse instrumento foi implementado, o número de crimes registrados caiu drasticamente. Alguns contestaram a relação de causa e efeito entre as duas coisas, dizendo que havia apenas concomitância, mas outros - como o respeitado sociólogo policial Eli Silverman, que publicou um estudo aprofundado sobre o Compstat (Silverman, 1999) - falavam de um "milagre de Nova York". De qualquer forma, muitas forças policiais imitaram esse sistema, nos Estados Unidos e no mundo, em particular na América Latina - Cidade do México, Caracas na Venezuela, Santiago do Chile etc. (Mitchel; Beckett, 2008). Esse foi particularmente o caso de Baltimore, cujo sistema Citystat aparece na famosa série de televisão The Wire.

Há alguns anos, porém, observa-se uma virada espetacular nas opiniões relacionadas ao Compstat. Até mesmo Silverman questiona seus efeitos recentes sobre os agentes de forma muito vigorosa. O sistema não os incentivaria mais a combater melhor o crime, mas, ao contrário, os estaria estimulando a burlar suas próprias regras. Para mostrar o desvio sistêmico do Compstat, Silverman e um ex-policial, John Eterno, desenvolveram e conduziram uma pesquisa estatística (Eterno; Silverman, 2012). O sindicato 
dos policiais aposentados deu-Ihes acesso aos arquivos de seus integrantes. A estes últimos, entregaram um questionário anônimo perguntando se sentiam que tinham transformado os números ou o próprio comportamento sob a influência dos números, de uma forma antiética, e se poderiam atribuir esses comportamentos à instauração do Compstat. Entre os entrevistados, mais da metade respondeu que, desde o Compstat, seus comportamentos realmente afastaram-se muito da norma, e ainda um quarto respondeu que se afastou bastante.

Esta pesquisa tem a virtude de mostrar - estatisticamente, o que é mais importante - que os agentes se reapropriaram das regras do Compstat da forma que lhes convinha, mas sem expressamente violar as regras. Contudo, ao fazer a pergunta em termos de transgressão da ética, há a inconveniência de emitir um julgamento moral negativo sobre uma atividade que, vista de outra forma, nada mais é do que uma defesa (Didier, 2018).

Julien Prévieux, artista plástico, impulsiona ao paroxismo essa liberdade gerada pela lacuna entre a regra e a sua aplicação ao fazer desta ocasião uma atividade artística. Tendo entrado em contato com jovens policiais da Brigada Anticrime de Paris por meio de uma rede amigável, propôs a eles a participação em uma oficina de desenho estatístico baseado em dados criminais observados em seus distritos. Os funcionários usaram as queixas recebidas em suas delegacias de uma série de infrações (furto, roubo etc.). Prévieux, então, explicou a eles como transformar esses dados em um diagrama de Voronoï, uma representação gráfica próxima às curvas isobáricas meteorológicas, que mostra o volume dos crimes através de uma maior densidade de traços. Os policiais exerceram o seu senso estético criando desenhos esplêndidos, nos fins de semana, nas horas de lazer (e, talvez, até no horário de trabalho, mas isso ninguém pode atestar). Os resultados foram apresentados em diversas ocasiões em locais de exibição de renome, o que, sem dúvida, atesta o caráter artístico dessas produções. Alguns foram vendidos a colecionadores e dois desenhos foram adquiridos por um museu francês de arte contemporânea. As margens de manobra 
persistentes na aplicação da norma policial adquiriram assim um valor artístico. Note-se, também, que esta atividade não é mais desinteressada do que aquela que lhes permitia apresentar bons resultados ao chefe e, assim, impulsionar suas carreiras e gerar bônus, uma vez que foi acordado entre o artista credenciado e os policiais que eles partilhariam igualmente o produto de potenciais vendas.

Detenhamo-nos também sobre um caso de artimanha com números no que diz respeito a negociações bipartidárias. Em 2009, Guadalupe, departamento francês localizado no Caribe, foi palco de um movimento popular muito importante de luta contra o aumento de preços. O LKP, grupo que deu origem ao movimento, não acreditava no índice de preços produzido pela administração pública e organizou um inquérito junto aos comerciantes para estabelecer o seu próprio índice. Eles se apresentam à mesa de negociações com esses dados, o que lhes permitiu obter vantagem sobre o governo assessorado pelo sindicato patronal. Mas, subitamente, ainda durante as discussões, o secretário de Estado Yves Jégo, que estava encarregado, foi afastado do processo, possivelmente por ser considerado demasiadamente aberto aos ativistas. Tratou-se, por parte do governo, de uma tentativa de transformar o marco das negociações, em cujo centro estavam as estatísticas, que lhe pareciam mal encaminhadas. O LKP reagiu, mudando o quadro por sua vez: atearam-se fogueiras nos principais cruzamentos de estradas da ilha, atos violentos foram praticados contra estabelecimentos de comércio, logo a violência popular veio a fortalecer os negociadores, e os números, locais. O estado não teve escolha senão conceder-lhes quase tudo o que eles pediam. Vê-se, aqui, que a finta pode ocorrer não de forma discreta, mas muito abertamente, em negociações relacionadas aos números, bem como em qualquer relação diplomática. Observa-se, também, que os números não são necessariamente uma alternativa à violência, contrariamente ao que um raciocínio weberiano sobre a racionalização do mundo sugere, mas, ao invés, podem tanto apoiar quanto ser apoiados por ela (Samuel, 2014). 
Esses casos sociológicos, artísticos e militantes ilustram um estatativismo de duas etapas. No primeiro nível, diz respeito a todos os agentes de uma administração e requer apenas recursos mínimos para ser colocado em prática; em particular, não requer know-how estatístico, uma vez que essa disciplina não é ensinada a policiais. Consiste na apropriação das regras de produção dos dados que servem para a autoavaliação a fim de, mais ou menos discretamente, mais ou menos abertamente, adaptá-los aos próprios interesses - que podem ir da pura fraqueza e bajulação às expectativas do chefe à mais orgulhosa independência na produção de obras de arte. A atividade estatística exige a codificação, sem a qual não haveria dados quantificados, mas a codificação, que, na maioria das vezes, é deixada nas mãos dos agentes mais dominados na hierarquia, deixa a esses, necessariamente, uma margem de manobra. Ela sempre Ihes abre possibilidades (Thévenot, 1983). Na medida em que, como hoje, o codificador é a própria pessoa que será avaliada pelos dados que codifica, ela usa essa possibilidade a seu favor. Ela se emancipa.

Num segundo nível, o estatativismo consiste em agregar todas essas práticas locais e mostrar que, por mais silenciosas que sejam, são tão comuns que se pode acusar toda a instituição de não perseguir realmente os objetivos que afirma. O estatativista deve, então, resolver o paradoxo de estar tanto dentro quanto fora da instituição. De fato, é impossível obter uma trilha das operações discretas dos codificadores sem estar com eles dentro da instituição e, ao mesmo tempo, deve-se ter acesso a uma tribuna pública para relatar num nível agregado o que se testemunhou. Essa é a razão pela qual os estatativistas tendem a trabalhar em pares ou em grupos, sendo o caso típico um policial associado a um sociólogo.

O efeito emancipatório desse estatativismo de segundo nível é duplo. Por um lado, procura evidenciar a possibilidade de uma realidade agregada diferente da que a instituição estabelece. Por exemplo, ele proclama: "não, ao contrário do que diz o Estado, mostramos que a criminalidade não está em declínio contínuo, porque esse declínio é mais bem explicado pelas 
manipulações de codificação feitas pela polícia". Em seguida, designa a possibilidade de uma realidade diferente da oficial. Ao mesmo tempo, denuncia, por outro lado, a capacidade da instituição de falsificar a realidade. Aqui, a declaração é: "o Estado tem meios para mentir para nós". Não é, então, sobre a realidade que pesa a dúvida, mas sobre a ação do Estado, que pode afirmar fazer uma coisa (lutar contra o crime) enquanto faz outra (manipular a opinião pública). Os estatativistas, então, denunciam as possibilidades de ação do Estado. Este último, é claro, não se deixa levar e, como pudemos mostrar em outro momento, ao retomar a estrutura dos lances de esgrima, a série de ataques e contra-ataques entre o Estado e os estatativistas está longe de terminar (Didier, 2011b).

O estatativismo, portanto, cobre uma variedade de práticas que vão desde o nível mais absolutamente individual ao mais coletivo. Consiste, por um lado, em libertar-se das regras que a autoridade impõe e, por outro, em revelar as mentiras que essa profere. Mas, nessa fase, o coletivo que ele constrói ainda não é um sujeito político, dotado de interesses e vontades próprias. Demonstraremos agora como essa subjetivação é estatisticamente possível.

\section{Sujeitos: defender novas categorias}

As recentes transformações na sociedade fizeram surgir novas categorias sociais. Como foi mostrado no caso dos executivos (Boltanski, 1982), para ganhar reconhecimento, os grupos sociais têm interesse em institucionalizarse estatisticamente. A invenção de novas categorias sociais - e sua crítica - já é, e deveria ser ainda mais, um importante campo do estatativismo. Diz respeito, por exemplo, ao caso de intelectuais em condições de trabalho precário, que detalharemos aqui; mas muitos outros exemplos vêm à mente, em particular as lutas de minorias étnicas, que merecem longas discussões.

Entre os mundos sociais mais fortemente afetados pelo desenvolvimento da governamentalidade neoliberal está o dos artistas e das profissões 
intelectuais. A invasão dessas profissões profissionais pelos instrumentos quantificadores do comando gerencial provoca novas experiências, das quais se pode evidenciar um caráter ambivalente, estranho, grotesco ou, inversamente, inovador e estimulante. Além disso, a invocação de experiências sociais que não se enquadram mais nos formatos disponíveis alimenta uma crítica às classificações oficiais. Acontece até mesmo de essas experiências estarem inseridas em um trabalho político e cognitivo voltado à construção de uma nova categoria social capaz de fazer demandas.

Os esforços para agrupar trabalhadores das artes e intelectuais em novas categorias sociais foram estudados por Cyprien Tasset (2014). Este pesquisador descreve duas tentativas nesse sentido, uma operada pela base e outra pelo topo. A estratégia da base é ilustrada no livro Les intellos précaires (2001), de Anne e Marine Rambach. Para essas autoras, "intelectuais precarizados" reúnem pessoas vulneráveis ao sistema econômico vigente, como pesquisadores sem status, artistas que sofrem para serem remunerados por suas atividades, jornalistas autônomos etc. Frequentemente, são pessoas formadas, nem sempre jovens, mas que não conseguem encontrar um emprego estável e, portanto, cujos estilos de vida não correspondem - longe disso -, ao que o seu nível de estudos lhes parecia prometer. O argumento de Rambach e Rambach é que essa situação transcende as habilidades e características individuais, e é atribuível a um modo de organização social que desvaloriza o trabalho intelectual e busca até mesmo torná-lo submisso. Dessa forma, elas estimulam os "intelectuais precarizados" a se unirem e a se contarem, tarefa a que se comprometem relacionando os resultados estatísticos que puderam obter durante sua investigação.

Em contraste com essa estratégia de baixo para cima, outros preferem partir do sentido contrário. Richard Florida (2002) por exemplo - embora não seja o único -, observa o surgimento de uma "classe criativa". Este grupo, embora muito maior do que o dos "intelectuais precarizados", assemelha-se a ele, exceto pelo fato de que as características negativamente conotadas por Rambach e Rambach são aqui valorizadas. Não precarizados, mas sempre 
dispostos a exercer sua liberdade no mercado de trabalho, os integrantes da classe estudada por Florida estariam em busca de oportunidades criativas. Eles não são passíveis de tornarem-se desnecessários, mas, ao contrário, são as pontas de lança do capitalismo cognitivo emergente.

Diante dessas tentativas de agregação de um sujeito coletivo, a artista brasileira Sonia Andrade oferece uma reconstituição de sua própria pessoa e, consequentemente, de cada um de nós. Ela apresentou, em 2019, na exposição ... às contas, no Museu de Arte Moderna do Rio de Janeiro, uma série de fios estendidos do chão ao teto, nos quais ela pendurou todas as contas que recebeu, classificadas pelas empresas cobradoras: água, eletricidade, gás, seguidas de coleções mais curtas, de televisão, telefone celular, provedor de internet. Caminhando pela exposição, muito mal iluminada, vemos um novo ser, muito estranho, feito apenas de cifras, no caso, monetárias, que é quem "conta" por todas essas empresas das quais somos "assinantes", às vezes, por muito tempo. Ela constrói, assim, um novo tipo de humano, quantitativo, consumidor e detido pelas cadeias da assinatura.

As lutas por definição entre as novas classes que pretendem incluir os intelectuais precarizados ou os criativos ou a exposição (e, neste caso, a denúncia discreta) de novos seres é uma frente importante de estatativismo envolvendo categorias estatísticas. Elas fazem parte da definição do sujeito que carregará o desejo e a práxis da emancipação. O grupo em questão aqui tem, por definição, recursos cognitivos bastante ricos que podem aparentemente compensar qualquer ignorância específica em estatística. Uma vez que os atores reconhecem a vantagem de passar por tais argumentos, eles reúnem os recursos de que precisam (cartas, pesquisa por "bola de neve", pesquisa documental selvagem), ou não hesitam em recorrer aos especialistas que os fornecem (consultores, sociólogos, estatísticos). Essas associações de competências também fazem parte da constituição do coletivo. Não se trata apenas de incluir muitos casos individuais em uma 
única categoria, é também uma questão de alinhar uma série de habilidades diversas a esse conjunto categórico.

A emancipação tem, portanto, duplo sentido: refere-se, em primeiro lugar, à atividade de constituição desse sujeito político coletivo e, em segundo lugar, ao alinhamento de uma série de possibilidades de ação desse sujeito. Difere do caso observado na polícia, em que o estatativismo é da ordem da revelação: ele rompe a realidade institucional que se autoproclama com resultados quantificados, ao mostrar a outra realidade de trapaças generalizadas e truques com números. Aqui, o estatativismo é positivo, busca provar que uma categoria existe de fato, quando não é reconhecida como tendo existência, e busca os meios de ação que permitem sua defesa. É claro que divulgação e afirmação não são mutuamente exclusivas e, em muitos casos, estão interligadas. No entanto, essas duas noções permitem traçar um eixo que vai da negação de uma realidade pré-existente à afirmação de entidades que ainda não existem. Mas, uma vez traçado o eixo, o mais interessante é compreender a complexidade das misturas observadas entre os dois polos extremos do continuum. É a isso que se dedica a última parte deste artigo, enfocando os indicadores.

\section{Finalidades: opor indicadores alternativos à instituição}

A governamentalidade neoliberal faz grande uso de indicadores. Um indicador é uma medida que transforma um fenômeno complexo em um valor único e simples que varia com o tempo. O índice de preços, por exemplo, deve indicar a variação do custo de produtos ao consumidor - e, portanto, do poder de compra das famílias - e permitir que as variações sejam acompanhadas. O indicador é usado para dar significado, para guiar a ação. Quem quiser ver aumento do poder de compra deve encontrar meios de controlar a evolução dos preços. Pode-se, por exemplo, escolher lutar contra a inflação monetária. Mas, por construção, um indicador retém do real apenas alguns aspectos considerados relevantes: aqui, apenas os produtos que são tidos em conta na "cesta" da família média, e não outros. 
Contribui assim para consolidar apenas alguns aspectos da realidade e, por conseguinte, negligenciar outros, que podem, no entanto, ser considerados prioritários segundo pontos de vista diferentes do indicador. Isso pode levar a graves crises políticas associadas a essas medidas. Assim, na Argentina, em 2007, demonstrou-se que o governo havia tentado manipular o índice de preços controlando apenas os preços tidos em conta pelos estatísticos do governo (convocados a divulgá-los) e não outros produtos. Em resposta, um novo índice surgiu, o "Billion Prices Project", desenvolvido por economistas privados do MIT, que "garimparam" os preços oferecidos na internet por um pequeno número de distribuidores e produziram uma agregação diferente, mas evoluindo dia a dia, e em grande parte contradizendo os números oficiais - que ficaram desvalorizados pelo escândalo (Lury; Gross, 2014). Muitas outras experiências estatativistas intervêm neste nível: para que a estatística oficial redistribua as prioridades de ação das instituições, militam para que se leve em conta outros aspectos da realidade e propõem indicadores alternativos.

Entre estes últimos, alguns apontam os efeitos perversos insuspeitados das políticas públicas ou gerenciais. Outros apontam para a importância e relevância de elementos que não são levados em consideração pelas medidas quantitativas oficiais. Alguns permitem contar o que (ainda) não conta, outros, discutir o indiscutível.

Os efeitos perversos podem ser contados de duas maneiras. Por um lado, os fatos obviamente desagradáveis são colocados em série para tornar visível o seu caráter sistemático e repetido. Um caso ainda mais eficaz, que se revela extremamente violento, é o caso do número de suicídios da France Telecom, a companhia telefônica francesa, que estava sendo privatizada de forma bastante brutal. Ivan Du Roy (2009) explica como sindicalistas tiveram que contar os suicídios que ocorreram na empresa para revelar a nocividade dos métodos gerenciais que tinham sido implementados.

Um caso ainda mais violento, desta vez ocorrido no Brasil, é a contagem de tiroteios nas favelas da região do Rio de Janeiro (Hirata; Couto; Grillo; Oliveira, 2017). De fato, nas últimas décadas, as trocas 
de tiros se multiplicaram no cotidiano dos moradores do Rio de Janeiro, principalmente nas favelas e periferias urbanas. Esses lugares vivem sob o "fogo cruzado" das ações violentas realizadas, de um lado, pelas forças policiais e, de outro, por grupos armados de traficantes e milicianos que controlam esses bairros. Embora as operações ad hoc sejam um dos principais motivos do fogo cruzado e das mortes violentas no Rio de Janeiro, não há dados disponíveis sobre essas ações que possam alimentar o debate público sobre segurança pública no Rio de Janeiro. Um projeto de pesquisa colaborativa entre pesquisadores e ativistas da cidade do Rio de Janeiro possibilitou a construção de um banco de dados sobre "operações pontuais", caracterizadas como incursões de órgãos de segurança (civis e militares) em favelas e bairros populares. ${ }^{6} \mathrm{O}$ projeto colaborativo visa, portanto, ampliar a reflexão coletiva sobre o problema da segurança pública no Brasil, construindo dados que qualifiquem a orientação do uso da força pelo Estado.

Quanto aos artistas, o grupo Superflex impulsiona as críticas aos indicadores de atividade ao nível do absurdo. O projeto Visitors Numbers consiste em sincronizar o mecanismo de contagem de visitantes da entrada de um museu com um grande placar de contagem pendurado no exterior, em destaque, como se esta informação fosse a mais importante de todas, como se a única coisa que importava era o museu ser muito visitado. Tratase, portanto, com amarga ironia, de destacar o modo neoliberal de gestão dos museus tanto que seu absurdo se torna tangível.

Entre as lutas que tomam os indicadores como armas ou como alvos, a dos sindicalistas da France Telecom deve ser tratada separadamente. Esses estatativistas tiveram essa ideia simples e devastadora de contar suicídios, o que certamente não requer habilidades estatísticas muito sofisticadas, mas sim qualidades humanas para encontrar as famílias de pessoas que acabaram com suas vidas, entender seu gesto desesperado e determinar se isso está ou não relacionado às suas condições de trabalho. Em outros casos, como o do projeto Fogo Cruzado, a luta contra os indicadores

${ }^{6}$ Ver o site https://fogocruzado.org.br/. 
institucionais implica conhecê-los o suficiente para analisá-los, decompô-los e recompô-los ou, como o Superflex, copiá-los e publicá-los em outro lugar. Este estatativismo requer certo conhecimento técnico. Sua eficácia depende, então, em grande parte, de saber por que os indicadores institucionais devem ser questionados, para que fim. Mais uma vez, o estatativismo é emancipatório na medida em que dá a possibilidade de fazer existirem certas realidades materiais, usando-as para certos objetivos, certos fins, que ainda estão por determinar.

Se voltarmos agora ao eixo composto pela revelação e pela afirmação, colocaremos a contagem dos suicídios do lado da revelação mais pura, nada afirmando senão o vazio da morte em face à ordem estabelecida, e então o ato artístico que consiste em ridicularizar esse sistema, que não é inteiramente negativo na medida em que oferece um novo lugar onde o sistema é exibido. Em seguida, vem a contagem dos tiroteios, que visa instituir outra medida de violência que leva em conta a produzida pela polícia. Muitos métodos de emancipação ocorrem, portanto, entre a destruição dos objetivos da instituição e a afirmação de fins alternativos.

\section{Outros números para outros possíveis}

O estatativismo é uma bandeira que reúne uma ampla variedade de práticas que têm em comum colocar a estatística a serviço da emancipação. Ao examinar as práticas mais contemporâneas, vimos que, em primeiro lugar, consistem em destacar e aproveitar todas as margens de liberdade que as regras de produção de cifras deixam aos agentes que a elas estão sujeitos. A estatística não é um corpo de leis imutáveis; ao contrário, quem a pratica aprende a brincar com ela sem cometer erros ou infrações. Em segundo lugar, o estatativismo consiste em usar vários métodos de quantificação para produzir grupos, sujeitos que surgem de uma aspiração de emancipar-se das condições a que estão sujeitos. A união faz a força, e as estatísticas são um dos primeiros alicerces dessas uniões. Por fim, consiste na redefinição dos objetivos perseguidos pelas instituições através da estatística. Não 
há razão para deixar que nos imponham os elementos da realidade que determinam a direção de nossas ações. Nos três casos, trata-se de ter em conta a autoridade dos fatos, mas sem jamais esquecer de que participamos de sua realização, em particular, graças à estatística, que nos permite articulá-la aos elementos do mundo aos quais temos acesso privilegiado. Essas práticas são transversais aos campos da arte, pesquisa e ativismo, todos os quais destacam o valor da estatística como argumento político.

Em particular, ela dissipa um dos mal-entendidos que dividem as potenciais oposições ao autoritarismo por números. Na verdade, embora a tradição romântica - desenvolvida com a industrialização e ainda viva hoje sob novas formas - seja uma fonte poderosa de crítica, ela tende a perceber as estatísticas apenas como uma emanação do "espírito frio e quantificador da era industrial", corporificado, por exemplo, pela personagem Thomas Gradgrind, em Dickens (Löwy; Sayre, 2010, p. 20). No entanto, a série de experiências estatativistas que reunimos inclui usos de números que conseguem manter contato com os mecanismos da cidade neoliberal, ao mesmo tempo em que se situam no nível da criatividade livre. Longe de estender o deserto existencial do utilitarismo, as invenções de protesto baseadas em números estendem a autonomia dos atores e podem, às vezes, apresentar, além de seu alcance emancipatório, um valor estético.

Acima de tudo, se uma certa forma de ativismo por números tornou-se hoje imprescindível, é, em primeiro lugar, pelo papel central desempenhado pelos instrumentos de quantificação na manutenção das fatalidades contra as quais as lutas pela emancipação se iniciam. Com efeito, a codificação, as categorias, os indicadores, enfim, todas as entidades estatísticas trazem uma contribuição decisiva para a construção de realidades que se sustentam. Denunciada acertadamente como o equipamento básico da "gaiola de ferro" da razão capitalista, a quantificação não deve, entretanto, ser desprezada em favor da exaltação das qualidades, das singularidades e do incomensurável. Tal renúncia seria um erro, porque a estabilidade restritiva das entidades estatísticas não é inabalável. Ao contrário, a atenção dada à instigação de medidas e indicadores revela seu caráter criativo e, muitas vezes, sua 
capacidade de eclipsar os mais antigos. Meio de reduzir incertezas ou abrir possibilidades práticas, a estatística também é uma encruzilhada disciplinar (matemática, ciências sociais, contabilidade, administração etc.) onde novos encontros podem ser estimulados.

Para finalizar, insistiremos, como Ted Porter (2013), no humor presente nessas abordagens estatativistas. Poderíamos, a priori, pensar que nada está mais longe do riso do que os números e, no entanto, não é o caso. Bakhtin (1982) nos permite entender o porquê. Ele mostra, a partir da obra de François Rabelais, também salpicada de jogos com números, que a estrutura do riso é ambivalente. Por um lado, deprecia a realidade oficial, por meio da ironia, da paródia, da hipérbole. Esta é uma conhecida alavanca humorística, operada em particular pelo Superflex. Mas isso não é tudo. Por outro lado, o riso acompanha a alegria da contraproposta, a materialização de uma nova realidade inesperada, a liberdade conquistada com os grilhões da realidade instituída, a transformação produtiva. Bakhtin fala da "força criadora do riso" (Bakhtin, 1982, p. 80). Ele escreve que "o riso rebaixa e materializa" (p. 29), é concomitante à degradação do oficial que era grande, e à materialização e à libertação, a partir do crescimento daquilo que mais condiz com a realidade. Os trabalhos de Le Chevalier, de Prévieux com a polícia do $14 \mathrm{O}$ arrondissement, ilustraram isso maravilhosamente. $\mathrm{E}$ também as obras de Pierre Bourdieu, quem dizia: "a sociologia deve ser divertida" e tentava fazer seus leitores sorrirem graças a "um novo uso da estatística" (Gollac, 2004, p. 29). A emancipação também pode assumir a forma de riso coletivo. ${ }^{7}$

A partir daí, "um outro número é possível": o que uma lógica hegemônica de quantificação estabeleceu, uma prática estatativista informada pode buscar desfazer ou, ao menos, abalar. Esse desvio da palavra de ordem da alter-globalização não é aqui o encantamento de um possível indeterminado,

${ }^{7}$ Bakhtin insiste que o riso rabelaisiano, o riso produtivo e afirmativo, é popular. É encontrado em carnavais, feiras, nos palcos de teatros públicos. Esse ponto nos permite reconsiderar a crítica que Boltanski (2009) qualifica de existencial e que atribui antes aos artistas que atuam na solidão romântica. A crítica existencial pode, sem dúvida, ser também humorística e coletiva. 
mas um apelo à produção de objetos quantificados que reconfigurem o possível em uma direção desejada e, espera-se, favorável à maioria. Claro, o destino de um indicador alternativo ou da enumeração de uma nova categoria social é incerto. Essas iniciativas podem "firmar-se" no espaço público ou passar despercebidas. O certo é que, em comparação com outras produções intelectuais, os debates e disputas relativos aos números na sociedade tendem a assumir um significado prático notável e, por que não, uma volta feliz - até mesmo cômica.

Emmanuel Didier é Diretor de Pesquisa do CNRS, Centre Maurice Halbwachs, Ecole Normale Supérieure-E.H.E.S.S. e Diretor do programa Médecin-Humanité na Ecole Normale Supérieure, Paris, França.

$\triangle$ edidier@ens.fr

Isabelle Bruno é professora de ciência política e membro júnior do Institut universitaire de France (IUF), CERAPS (CNRS / Universidade de Lille), Lille, França.

$\triangle$ isabelle.bruno@univ-lille.fr

\section{Referências}

1. BAKHTIN, Mikhail. L'œuvre de François Rabelais et la culture populaire au Moyen Age et sous la Renaissance. Paris: Gallimard, 1982.

2. BOLTANSKI, Luc. Les cadres : la formation d'un groupe social. Paris: Éditions de Minuit, 1982.

3. BOLTANSKI, Luc. De la critique. Précis de sociologie de l'émancipation. Paris: Gallimard, 2009.

4. BOLTANSKI, Luc. Quelles statistiques pour quelles critiques ? In: BRUNO, Isabelle ; DIDIER, Emmanuel; PRÉVIEUX, Julien (éds.) Statactivisme : comment lutter avec des nombres. Paris: Zones, 2014. p. 33-50.

5. BORIS, Samuel. Statistics and political violence: reflections on the social conflict in 2009 in Guadeloupe. Partecipazione \& Conflitto, v. 7, n. 2, p. 237-257, 2014.

6. BOURDIEU, Pierre. Sur I'Etat. Cours au Collège de France (1989-1992). Paris: Seuil, 2012. 
7. BOURDIEU, Pierre; HAACKE, Hans. Libre échange. Paris: Le Seuil/Les Presses du réel, 1994.

8. BOURDIEU, Pierre; PASSERON, Jean-Claude. Les héritiers : les étudiants et la culture. Paris: Les Éditions de de Minuit, 1964.

9. BRUNO, Isabelle. Défaire I'arbitraire des faits. De l'art de gouverner (et de résister) par les "données probantes". Revue Française de Socio-Économie, n. 2, p. 213-227, 2015. https://doi.org/10.3917/rfse.hs1.0213

10. BRUNO, Isabelle; DIDIER, Emmanuel. Benchmarking. L'État sous pression statistique. Paris: La Découverte, 2013.

11. BRUNO, Isabelle; DIDIER, Emmanuel; PRÉVIEUX, Julien (dirs.). Statactivisme. Comment lutter avec des nombres. Paris: Zones, 2014.

12. BRUNO, Isabelle; DIDIER, Emmanuel; VITALE, Tommaso. Statactivism: forms of action between disclosure and affirmation. Partecipazione $\boldsymbol{\&}$ Conflitto, v. 7, n. 2, p. 198-220, 2014.

13. CAILLÉ, Alain. De l'idée même de richesse. Paris: La Découverte, 2012.

14. CHAMPY, Florent. La Sociologie des professions. Paris: Presses Universitaires de France, 2009.

15. DESROSIÈRES, Alain. Managing the Economy. In: ROSS, Dorothy; PORTER, Theodore M. The Cambridge History of Science, v. 7: The modern social sciences, 2003. p. 553-564.

16. DESROSIÈRES, Alain. Pour une sociologie historique de la quantification. Paris: Presses de l'École des Mines, 2008.

17. DESROSIÈRES, Alain. La statistique, outil de libération ou outil de pouvoir ? In: BRUNO, Isabelle; DIDIER, Emmanuel; PRÉVIEUX, Julien (éds.) Statactivisme : comment lutter avec des nombres. Paris: Zones, 2014. p. 51-66.

18. DIDIER, Emmanuel. L'État néolibéral ment-il ? "Chanstique" et statistiques de police. Terrain, n. 57, p. 66-81, 2011.

19. DIDIER, Emmanuel. Globalization of quantitative policing: between management and statactivism. Annual Review of Sociology, v. 44, n. 1, p. 515534, 2018.

20. DIDIER, Emmanuel. Politique du nombre de morts. AOC média, 16 avril, 2020. https://aoc.media/opinion/2020/04/15/politique-du-nombre-de-morts/

21. DIDIER, Emmanuel. Quantitative marbling, New conceptual tools for the socio-history of quantification. Anton Wilhelm Amo Lectures, n. 7. Halle: MartinLuther-Universitat Halle-Wittenberg Press, 2021. https://wcms.itz.uni-halle.de/ download.php?down $=58212$ \&elem $=3346065$

22. DU ROY, Ivan. Orange stressé. Paris: La Découverte, 2009. 
23. ECF - Ecole de la Cause Freudienne (éd.). Quelle liberté pour le sujet à l'époque de la folie quantitative. Paris : Pleins Feux, 2008.

24. ETERNO, John E.; SILVERMAN, Eli B. The crime numbers game: management by manipulation. New York: CRC Press, 2012.

25. FLORIDA, Richard. The rise of the creative class. And how it's transforming work, leisure and everyday life. New York: Basic Books, 2002.

26. GENEL, Katia. L'autorité des faits : Horkheimer face à la fermeture des possibles. Tracés, v. 24, n. 1, p. 107-119, 2013.

27. GOLLAC, Michel. La rigueur et la rigolade. À propos de I'usage des méthodes quantitatives par Pierre Bourdieu. Courrier des statistiques, n. 112, p. 29-36, 2004.

28. GORI, Roland; CASSIN, Barbara; LAVAL, Christian (dir.). L'Appel des appels pour une insurrection des consciences. Paris: Mille et une nuits, 2009.

29. HAACKE, Hans; BECKER, Howard S.; BURNHAM, Jack; WALTON, John. Hans Haacke: framing and being framed; 7 works 1970-75. Halifax: Press of the Nova Scotia Collage of Art and Design, 1975.

30. HIRATA, Daniel; COUTO, Maria I.; GRILLO, Carolina; OLLIVEIRA, Cecilia. Échanges de tirs. La production de données sur la violence armée dans des opérations de police à Rio de Janeiro. Statistique et société, v. 7, n. 1, p. 31-39, 2019.

31. LÖWY, Michael; SAYRE, Robert. Esprits de feu. Figures du romantisme anticapitaliste. Paris: Éditions du Sandre, 2010.

32. LURY, Celia; GROSS, Ana. The downs and ups of the consumer price index in Argentina: from national statistics to big data. Partecipazione \& Conflitto, v. 7, n. 2, p. 258-277, 2014.

33. MILNER, Jean-Claude. La Politique des choses. Court traité politique I. Lagrasse: Verdier, 2011.

34. MITCHELL, Katharyne; BECKETT, Katherine. Securing the global city: crime, consulting, risk, and ratings in the production of urban space. Indiana Journal of Global Legal Studies, v. 15, n. 1, p. 75-99, 2008.

35. PORTER, Theodore. Funny numbers. Culture Unbound: Journal of Current Cultural Research, n. 4, p. 585-598, 2013.

36. RAMBACH, Anne; RAMBACH, Marine. Les intellos précaires. Paris: Fayard, 2001.

37. SALTELLI, Andrea et al. Five ways to ensure that models serve society: a manifesto. Nature, n. 582, p. 482-484, 2020.

38. SILVERMAN, Eli B. NYPD battles crime. Innovative strategies in policing. Boston: Northwestern University Press, 1999. 
39. PIRIOU, Jean Paul. L'indice des prix. Paris: La Découverte, 1992.

40. STATISTIQUE ET SOCIETE. Paris. Société Française de Statistique (SFdS), v. 7, n. 1, Juin 2019.

41. TASSET, Cyprien. Les "Intellos précaires" et la classe créative. In: BRUNO, Isabelle; DIDIER, Emmanuel; PRÉVIEUX, Julien (éds.) Statactivisme : comment lutter avec des nombres. Paris: Zones, 2014. p. 117-132.

42. THEVENOT, Laurent. L'économie du codage social. Critiques de I'économie politique, n. 23-24, p. 188-222, 1983.

43. TOPALOV, Christian. Naissance du chômeur : 1880-1910. Paris: Albin Michel, 1994.

44. TOUCHELAY, Béatrice. Les ordres de la mesure des prix. Luttes politiques, bureaucratiques et sociales autour de l'indice des prix à la consommation (19112012). Politix, v. 27, n. 105, p.117-138, 2014.

Recebido em: 17 dez. 2020

Aceito em: 15 mar. 2021 